\title{
Issues in Instructional Design of Massive Open Online Courses (MOOC)
}

\author{
Sun Dan \\ College of Teacher Education \\ Zhejiang Normal University \\ Jinhua, China \\ cone.sun@yahoo.com
}

\author{
Jiang Fan \\ Institute of Educational Science \\ Zhejiang Normal University \\ Jinhua, China \\ 1017299081@qq.com
}

\begin{abstract}
MOOC is considered as a new kind of online education, so far, the international academic community has been conducted series of researches based on the mechanism of MOOC. However, there is little study about the issues in Instructional Design of MOOC. The paper analyzes the current development and point out the bottleneck of instructional design of MOOC. By summarizing the international view of MOOC, paper also analyzed different aspects of MOOC in accordance with the ten principles of instructional design proposed by scholar Merill and Margaryan, and finally come up with some ideas for future research.
\end{abstract}

Keywords-MOOC; Principles of Instructional Design; Teaching Issues; Educational Technology

\section{INSTRUCTIONAL DESIGN OF MOOC}

A massive open course (MOOC) is an online course aimed at unlimited participation and open access via the web [1]. The word MOOC was first used to describe an open courses 'Connectivism and Connective Knowledge', which was developed by George Siemens and Stephen Downes at University of Manitoba, more than 2,200 people around the world participate in this course. A growing number of universities around the world offer MOOCs since 2012. MOOCs have been recognized as a major advancement in higher education. For example, Legon mentioned the 'Quality Matters' that MOOCs actually provide a quality service, because the course is designed for typical students and integrate with the higher education courses. However, critics like Daniel claimed that the lack of novelty in MOOC, as well as its extreme exaggeration of the impact of education and learning scale. 2013 The Observatory of Borderless Higher Education (OBHE) mentioned the specific focus of MOOC is to emphasize the 'high-quality content', but did not pay much attention to the instructional design(ID) and the overall learning experience. Some people suggest that MOOCs could provide public indices of quality, which may expose weaknesses of elite education in teaching and learning.

\section{THE BOTTLENECK OF MOOC}

The United States has become a pioneer and leader in the world higher education network, especially the network development of higher education has won a worldwide attention [2]. Sloan Consortium Report has been seen as a 'window' to show the characteristics of network development of higher education. In year 2012, Stanford University, Harvard University and other famous universities have released courses in massive open online courses Coursera, Udacity and Edx. 'New York Times' said that 2012 was the "MOOC year" [3]. Sloan Consortium captures the importance of network for higher education and launched an investigation.

\section{A. Popularity and role of MOOC is unclear}

Most colleges and universities still hold a uncertain view of MOOC. 2015 The Sloan Consortium report compares the MOOC data in year 2012, 2013 and 2014, as shown in Table 1.

TABLE I. UNIVERSIT JOIN RATIO OF MOOC (UNIT: \%)

\begin{tabular}{|l|l|l|l|l|l|}
\hline & $\begin{array}{l}\text { Already } \\
\text { joined }\end{array}$ & $\begin{array}{l}\text { Prepare } \\
\text { to join }\end{array}$ & $\begin{array}{l}\text { Haven't } \\
\text { decided }\end{array}$ & Don't join & $\begin{array}{l}\text { Sum } \\
\text { up }\end{array}$ \\
\hline 2012 & 2.6 & 9.4 & 55.4 & 32.7 & 100 \\
\hline 2013 & 5.0 & 9.3 & 52.7 & 33.0 & 100 \\
\hline 2014 & 8.0 & 5.6 & 39.9 & 46.5 & 100 \\
\hline
\end{tabular}

Table 1 shows that during the year 2012-2014, there are increasing numbers of colleges and universities have joined MOOC. As Tanya Roscorla [4] said 'MOOC is a poppy which lure people to join the higher education network.' Investigation report about higher Education Research Institute and companies like Coursera shows the main reasons why more institutions join MOOC are shown as follows[5][6]:

1) MOOC is an important way for institution to improve teaching quality and repuation

2) MOOC could bring more economic profit for institution some college could extract $6 \%$ to $15 \%$ or even $20 \%$ proft from MOOC class.

3) American government give an great support for MOOC, such as The National Science Foundation had put 20 thousand dollars to promote development of MOOC.

RyRivard [7] believe that dropout rate is reaching $90 \%$ which make colleges doubt about MOOC. Richard [8][9] hold the view that the reason why there are still doubt about MOOC in the college are as follows: 
1) There are still a few colleges which support and develop MOOC courses, and its operative mechanism is not mature.

2) Due to limitations of teachers and finance, most colleges and universities cannot join MOOC, and these universities do not want to explore and improve methods of MOOC system

3) Universities cannot provide comprehensive supporting services (such as lacking of interaction between students in $M O O C)$, which is likely to cause loneliness, increase anxiety and no sense of belonging, universities also cannot provide appropriate interactive platform for learners.

4) Business model of MOOC is not yet mature.

\section{B. Effect of MOOC is unclear}

TABLE II. RATIO OF COLLEGE WHO AGREES WITH THE ABOVE VIEW (UNIT: \%)

\begin{tabular}{|c|c|c|c|}
\hline & $\begin{array}{c}\text { MOOC is very } \\
\text { important for } \\
\text { high school } \\
\text { online education }\end{array}$ & $\begin{array}{c}\text { MOOC is a } \\
\text { sustainable } \\
\text { development for } \\
\text { online course }\end{array}$ & $\begin{array}{c}\text { Certificate which MOOC } \\
\text { provide will bring about } \\
\text { a disorder to higher } \\
\text { education }\end{array}$ \\
\hline 2012 & 49.8 & 28.3 & 52 \\
\hline 2013 & 44 & 23.2 & 64 \\
\hline 2014 & 27.9 & 16.3 & No data \\
\hline
\end{tabular}

Table 2 show that during year 2012-2014, the proportion of supporting MOOC is very important to online course has been declining. Some university teachers clearly hold opposite view to providing MOOC. For example, some teachers think MOOC should not be separated from the face to face teaching, and it should be a complement to face to face teaching; other teachers think MOOC is lacking of accountability. Who should be responsible for low course completion rate? Is colleges, teachers or MOOC platform provider? [10]

The proportion of universities which support the view that MOOC could solve sustainable problem of online course has also showed a downward trend during year 2012-2014, which shows more and more university teachers hold uncertain view about the sustainability of the MOOC. Jamie Beckett [11] proposed a series of questions: Is course structure MOOC of complete? Is teaching content of MOOC updating timely? Is evaluation of MOOC close enough to the students' actual learning situation?

Bottlenecks of MOOC which needs to be solved in the future are shown as follows:

1) Well-established supporting system should be. Such as the relationship between credits of MOOC and traditional education.

2) Scientific operating mode to. How to ensure the most economic profit between government, businesses and universities?

3) Complete certification system. What is the difference between MOOC credits and traditional education?

4) Strengthened discipline of online education. More and more higher education institutions will develop network protocol to regulate the development of online higher education.
5) Improved effect of online course. Excellent teaching effect is the key to online education.

\section{PRINCIPLES AND MODELS OF ID OF MOOC}

ID(Instructional Design) is a teacher in order to complete certain teaching tasks and optimize the teaching effectiveness, taking teaching system as its object, using a systematic approach to analyze teaching problems and constraints, selecting and identifying activities and process of teaching plan. The importance of education for instructional design is selfevident [12]. MOOC subordinates to the concept of online courses, thus instructional design is also an extremely significant for MOOC.

Chinese scholars Wang Zhuli [13] divide ID of MOOC into following parts: (1) Pre-learning Analysis: it includes analysis of traditional teaching and learning, as well as the relationship between teacher and student, student and student, and student and resource under network environment; (2) Instructional Object Design: it includes initial identified objectives of teaching and learning, which should take learner's strong personal will into consideration; (3) Strategy Design: it mainly contains strategy for constructing learning resource (type of resource, platform module), learning process (preparation, implementation and assessment) and learning activities (online and offline activities). (4) Evaluation Design (evaluation of learners, evaluation of curriculum effect). As shown in Fig.1.

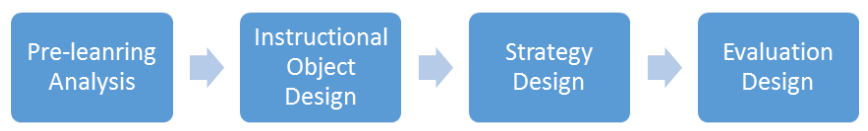

Fig. 1. ID of MOOC (Wang Zhuli)

Kopp Lackner [14] mentioned it is more difficult to obtain timely feedback from teachers and students in online course, especially in the MOOC, because of the openness of curriculum and diversification of student. He designed teaching guide for MOOC instructional design through combining existing theories, which includes (1)Core Requirements (considering different target audiences and platform tool settings); (2)Curriculum Framework (it is important to portion the content into eight to ten course units, the units should consists of the same environments or parts, such as testing, resource, communication section and so on. The first unit should be designed as a welcome and socializing unit, in order to get to know the audience and the platform); (3)Participant Requirements (set compulsory and elective curriculum unit, timely update performance of learners); (4)Assignments (clear assignments and evaluation criteria); (5) Media design (split the content into portions of five to ten minutes video clip, resource and tools should be designed to meet the different mobile device, and also the viewing habits of digital immigrants); (6)Communication (open spaces and channels for communication, create a newsletter to keep the participation on the track); (7)Resources (available resources, online counselors, collect student feedback). As shown in Fig. 2. 


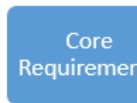

早

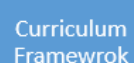

\begin{tabular}{c}
$\begin{array}{c}\text { Curriculum } \\
\text { Framewrok }\end{array} \Rightarrow \begin{array}{c}\text { Participant } \\
\text { Requirements }\end{array}$ \\
\hline
\end{tabular}

Participant
Requirements

Requirements
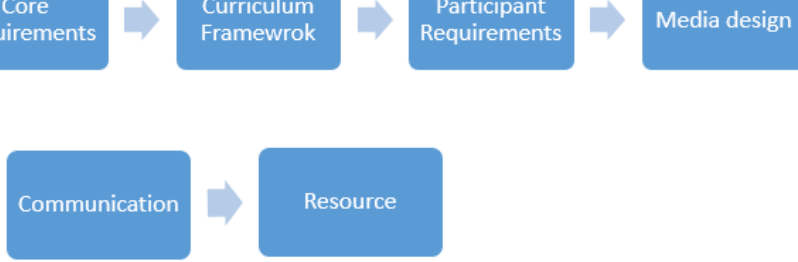

Fig. 2. ID of MOOC (Kopp Lackner)

Norma I.Scagnoli proposed five key factors of MOOC instructional design: (1) novelty and balance of past experience, regardless of past experience of learners, learning content should be able to attract their attention. (2) Diversified sources input: provide rich resources (video, audio, text, e-books, digital resources, etc.) to help learners to construct understanding about knowledge. (3)Check understanding and in-depth thinking: through independent classification of activities, so that the participants could have a deep understanding about the topic of the week. (4) Learning opportunities in community and participation motivation: to encourage participants to choose interesting topics to participate in learning activities. (5) Planning Intellectual Property: Students are encouraged to create a personal digital learning space to save their learning resources. As shown in Fig. 3.
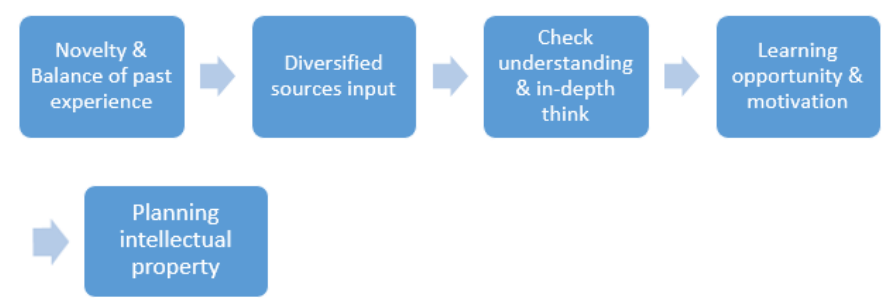

Fig. 3. 5 key factors of MOOC ID

\section{EVAluation CRITERIA FOR ID OF MOOC}

Although learning experience of students are very important, but the quality of ID is a key indicator and prerequisite for effective learning. ID is a crucial part in overall quality and effectiveness of learning experience. However, most courses did not take ID as the main evaluative principle. This is mainly because assessment is mostly about leaners' view of courses quality, whereas learners usually do not have the expertise to evaluate the ID. Therefore, MOOC evaluation criteria drawn by ID experts are an important way to measure the quality of MOOC ID. But there is no study relating to the ID quality of MOOCs [15].

Merrill Lynch [16] proposes 'First Principles of Instruction' which mentions five important criteria for evaluation of ID of MOOC, as shown in Table 3.
TABLE III. FIVE-PRINCIPLE FRAMEWORK (MERRIL)

\begin{tabular}{|c|c|}
\hline $\begin{array}{l}\text { 1. Task/Problem- } \\
\text { Centered }\end{array}$ & $\begin{array}{l}\text { Students learn more when the instruction is centered } \\
\text { on relevant real-world tasks or problems, including a } \\
\text { series of tasks or problems that progress from simple } \\
\text { to complex. }\end{array}$ \\
\hline 2. Activation & $\begin{array}{l}\text { Students learn more when they are directed to recall } \\
\text { prior knowledge, to recall a structure for organizing } \\
\text { that knowledge, or are given a structure for organizing } \\
\text { new knowledge. This activation can also include a } \\
\text { foundational learning experience upon which new } \\
\text { learning can be based. }\end{array}$ \\
\hline 3. Demonstration & $\begin{array}{l}\text { Students learn more when new knowledge is } \\
\text { demonstrated to them in the context of real-world } \\
\text { tasks or problems. The knowledge that is demonstrated } \\
\text { is both informational and skill-based. Demonstration is } \\
\text { enhanced when it adheres to research-based principles } \\
\text { of e-learning. }\end{array}$ \\
\hline 4. Application & $\begin{array}{l}\text { Students learn more when they perform real-world } \\
\text { tasks or solve real-world problems and receive } \\
\text { feedback on and appropriate guidance during that } \\
\text { application. }\end{array}$ \\
\hline 5. Integration & $\begin{array}{l}\text { Students learn more when they are encouraged to } \\
\text { integrate their new knowledge into their life through } \\
\text { reflection, discussion, debate, and/or presentation of } \\
\text { new knowledge. }\end{array}$ \\
\hline
\end{tabular}

Merrill's First Principles of Instruction focus on learning activities, these are augmented by a set of five further focused on learning resources [17].

6. Collective knowledge: Learning is promoted when learners contribute to the collective knowledge.

7. Collaboration: Learning is promoted when learners collaborate with others.

8. Differentiation: Learning is promoted when different learners are provided with different avenues of learning, according to their need.

9. Authentic resources: Learning is promoted when learning resources are drawn from real-world settings.

10. Feedback: Learning is promoted when learners are given expert feedback on their performance.

Anoush Margaryan [18] found that most MOOC (whether xMOOCs or cMOOCs) rate low in the above-mentioned principles. In his research, each class is represented by score range $0-72,0$ indicates no response to any of the principles and organizational standards, 72 represent all of the principles and standards have largely been reflected. Research shows that the score of 76 classes are between $0-28$. Principles reflected in MOOC course were discussed as follow.

To what extent are MOOCs problem-centered? Research examined the relationship between MOOC goal and solving real-world problem. It is found that there are numerous questions and not only one true answer. Most MOOC class (67/76) did not prove problem-centered. Only 4 cMOOCs and 4 xMOOCs classes include learning activities based around authentic, ill-structured and divergent problems. 
Do MOOCs enable leaners to apply their new knowledge or skill to solve problem? 68 of 76 classes did not require student to combine previous knowledge with current curriculum resource. Only 1 xMOOCs and 6 cMOOCs combine both. For instance, before a physic class start, learning activity demand participant to conduct real experiment or diver their own understanding combined with daily life.

To what extent do MOOCs encourage learners to integrate new knowledge or skill? There was limited evidence of the integration principle within the MOOC.

Do MOOCs encourage learners to contribute to collective knowledge? The principle was operationalized as the extent to which the learning activities required participants to learn from each other. In the majority of courses, learning activities did not require participant to build on others' work.

Do MOOCs provide expert feedback to learners? Study examined if the course include feedback. Only expert instructor feedback was taken into consideration and it shows that none course had instructor feedback. Analysis of discussion forum showed that interactions were general and non-specific rather than providing deep and targeted expert feedback on a learner's performance on specific learning activities and tasks.

\section{FINDING AND CONCLUSION}

With widespread of MOOCs, in order to meet the different requirements of learners and educators increasingly attention has been paid to its scientific principles of MOOC instructional design. However, quality of MOOC instructional design is not satisfactory. Several principles mentioned in the article are more than significant for instructional design of MOOC. In the large-scale online courses, implementations of several principles are very essential. Such as provide learners with high-quality and learner-friendly feedback. If academic institutions and universities continue to provide MOOCs, they must respect the basic principles and rethink instructional design model of MOOC. Many learners are directed at the reputation of the university or academic institution when choosing MOOC to learn, who expecting famous traditional institutions with rigor and quality.

Although we can speculate the reasons instructional design principles of MOOCs achieve a lower rate, but we cannot provide enough evidence to prove the poor teaching and learning of MOOCs. There are a series of potential causes. For example, MOOCs instructors and designers may lack of modern teaching and learning theory of instructional design principles of MOOC. Or, even though they are very clear about the principles and give an implementation in their daily curriculum, but did not do the same in MOOCs. Or, teachers may be subject to its marketing aspect rather than teaching objectives when providing MOOCs. We did not review the background, motivation and which individuals or institutions have developed these MOOCs, thus we may not explain the weakness of instructional design of MOOC. Future studies may investigate the instructional design concepts, goals and motivations of institutions and individuals who have been developing MOOCs, to provide MOOCs with a perspective future and high assurance of instructional design quality.
Ten principles mentioned by scholars Merill and Margaryan are an important criterion for evaluating the quality of teaching, so that it can be used to evaluate any form of curriculum (including the MOOCs and other online courses). These ten principles represent a collection of what we know about effective teaching theory. Thus, MOOC should strive to follow these guidelines as much as possible. However, we will find it hard to comply with all of the principles in one class, and it is more necessary to apply these principles in some courses than others. Merrill Lynch believes that "with the implementation of these principles, we are going to enjoy an increasingly effective teaching strategy." Paper combining these ten principles of instructional design of MOOC could have a certain significant influence in directing teaching and learning, helping to design and improve higher quality of learning strategies. These principles can serve as a control standard to evaluate and improve the quality of MOOCs. Existing assessment frameworks are normally focusing on views and learning experience of learners, and often overlooked quality of instructional design of MOOC. Instructional design is an important variable in the overall quality of a course. Although the current MOOCs is still in the experimental stage in the worldwide, the application of instructional design principles will play a profound or even decisive impact in the development of MOOC.

\section{REFERENCES}

[1] Massive open online course [OL]. <https://en.wikipedia.org/wiki/Massive_open_online_course>

[2] Bai Bing, "Interpretation of the 21st century online higher education," Distance Education in China, 2008, vol 6:74-78. In Chinese.

[3] Laura P. The Year of the MOOC [OL]. <http: //crookedtimber.org/2012/11/05/the-year-of-the-mooc/>.

[4] Online education proves critical to university strategy[OL]. $<\mathrm{http}: / /$ www.centerdigitaled.com/news/Online-Education-UniversityStrategy.html>.

[5] Online education proves critical to university strategy[OL]. $<$ http://www.centerdigitaled.com/news/Online-Education-UniversityStrategy.html>.

[6] Undergraduate teaching faculty: The 2013-2104 HERI faculty survey [OL]. <http://heri.ucla.edu/pr-display.php?prQry=151.>.

[7] Ry R. Measuring the MOOC Dropout Rate[OL]. <http://www.insidehighered.com/news/2013/03/08/researchers-explorewho-taking-moocs-and-why-so-many-dropout\#sthash.soK1qVwF.dpbs/.>

[8] Philip D. MOOC: Communicative interactivity and multimedia[OL]. <http://www.revistacomunicar.com/pdf/call/call-44-en.pdf.>

[9] Jeffrey R. Young. Inside the coursera contract: How an upstart company might profit from free courses[OL].

[10] Can the current model of higher education survive MOOCs and online learning?[OL].<http://www.educause.edu/ero/article/can-current-modelhigher-education-survive-moocs-and-online-learning.>.

[11] Jamie B. Online learning: Will technology transform higher education?[OL].<http://engineering.stanford.edu/news/online-learningwill-technology-transform-higher-education.>.

[12] Wang Chunhua, "Instructional Design and its rational limits," Shandong Normal University, 2014. In Chinese.

[13] Wang Zhuli, "Instructional Design of MOOC," < http://blog.sina.com.cn/s/blog_4bff4c090102v7pr.html > In Chinese 
[14] Elke Lackner and Michael Kopp, "Do MOOCs need a Special Instructional Design?"

[15] Anoush Margaryan. "Instructional quality of Massive Open Online Courses (MOOCs)", Computer \& Education, 2015,(80):77.

< http://www.researchgate.net/publication/263784897,2014-07.>
[16] Merrill, M. D, First principles of instruction: Identifying and designing effective, "efficient and engaging instruction. Hoboken, NJ: Pfeiffer/John Wiley \& Sons, (2013).

[17] Margaryan, A. Work-based learning: A blend of pedagogy and technology. Saarbruecken: AV Akademikerverlag.

[18] Anoush Margaryan, "Instructional quality of Massive Open Online Courses (MOOCs)," Computer \& Education, 2015,(80):77. 